\title{
INFLUENCE OF INJECTION RATE OF HYPERBARIC BUPIVACAINE 0.75\% ON SPINAL ANAESTHESIA IN ELDERLY PATIENTS WITH LOWER LIMB ORTHOPAEDIC SURGERIES. A RANDOMIZED CONTROLLED TRIAL.
}

\footnotetext{
1. MBBS, MCPS, FCPS

(Anaesthesiology)

Associate Professor of Anaesthesiology

Department of Anaesthesia

Fauji Foundation Hospital,

Rawalpindi.

2. MBBS, MCPS,

Department of Anaesthesia

Fauji Foundation Hospital,

Rawalpindi.

3. MBBS

Department of Anaesthesia Fauji Foundation Hospital,

Rawalpindi.
}

Correspondence Address:

Brig (r) Dr Manzoor Ahmad Faridi Associate Professor of

Anaesthesiology

FUMC, Rawalpindi.

faridi548@gmail.com

Article received on:

03/05/2019

Accepted for publication:

15/07/2019

Received after proof reading: $31 / 07 / 2019$

\begin{abstract}
Manzoor Ahmed Faridi (Retd) ${ }^{1}$, Shaheen Mehmood ${ }^{2}$, Muhammad Safi Ur Rehman ${ }^{3}$
ABSTRACT... To determine the effect of speed of hyperbaric bupivacaine $(0.75 \%)$ injection on clinical characteristics of spinal anaesthesia in elderly patients undergoing lower limb orthopaedic surgeries. Study Design: Prospective, randomized, double-blind study. Setting: This study was conducted in the operating theatre of Fauji Foundation Hospital, Rawalpindi. Period: August 2018 - March 2019. Materials and Methods: 60 elderly patients undergoing lower limb orthopaedic surgery were randomized into two groups based on injection rate (fast and slow). $1.5 \mathrm{ml}$ of $0.75 \%$ hyperbaric bupivacaine was injected over 5 seconds (fast group) and 50 seconds (slow group). Study was undertaken after taking permission from institutional ethical review committee. Level of sensory block, motor block, and systolic blood pressure were recorded at pre-specified intervals. Incidences of hypotensive episode, nausea, phenylephrine and antiemetic use were also documented. Results: Our study did not reveal any difference in maximum level of sensory block attained (fast $=$ median $\mathrm{T} 4$, interquartile range [T4-T6] vs slow $=\mathrm{T} 4$ [T4-T6], $\mathrm{P}=0.77$ ). There was no difference in mean time (minutes) to reach $\mathrm{T} 10$ sensory level (fast $=2.5 \pm 1.2$ vs slow $=2.2 \pm 0.8, P=0.27$ ); maximum sensory level (fast $=4.2 \pm 1.5 \mathrm{vs}$ slow $=3.8 \pm 1.2, \mathrm{P}=0.26)$ and maximum motor block level $(\mathrm{min})$ (fast $=5.9$ \pm 1.4 vs slow $=5.7 \pm 1.2, \mathrm{P}=0.56$ ). The rate of hypotension (fast $=8 / 30$ vs slow $=4 / 30, \mathrm{P}$ $=0.33$ ), nausea (fast $=5 / 30$ vs slow $=3 / 30, P=0.99$ ) and phenylephrine use (fast $=5 / 30$ vs slow $=3 / 30, P=0.71$ ) and antiemetic requirement (fast $=1 / 30$ vs slow $=2 / 30, P=0.99$ ) was also alike. Conclusion: There is no effect of injection speed of intrathecal $(0.75 \%)$ bupivacaine on the clinical features of spinal anaesthesia in older patients undergoing lower limb orthopedic surgery.
\end{abstract}

Key worlds: Bupivacaine, Elderly Patients, Orthopedic Surgery, Speed of Spinal Injection, Spinal Anesthesia,

Article Citation: Faridi MA, Mehmood S, Safi Ur Rehman M. Influence of injection rate of hyperbaric bupivacaine $0.75 \%$ on spinal anaesthesia in elderly patients with lower limb orthopaedic surgeries. A randomized controlled trial. Professional Med J 2019; 26(8):1251-1255. DOI: 10.29309/TPMJ/2019.26.08.3691

\section{INTRODUCTION}

With the global improvement in healthcare and resulting increase in life expectancy, a greater number of older patients requiring surgery and anaesthesia are seen. Such patients have increased risk of mortality and morbidity due to changes in pharmacokinetics and pharmacodynamics and presence of comorbidities. ${ }^{1}$ Spinal anesthesia, most commonly with bupivacaine, is frequently utilized in geriatric orthopaedic patients. ${ }^{2}$ There is a significant drop in cardiac output and blood pressure in geriatric patients after getting spinal anaesthesia due to a decrease in stroke volume. Elderly patients due to reduced physiological compensatory mechanisms and decreased cardiac reserve are more susceptible to adrop in blood pressure. ${ }^{4}$ Thus, most common side effects associated with this technique include hypotension and decreased heart rate (bradycardia). ${ }^{3}$ It can be challenging to maintain adequate blood pressure in elderly patients while reaching the required level of sensory block. It is hypothesized that the rate of injection is an important factor in these hemodynamic changes. So far, the results have been inconclusive. While some studies have showed a higher level of sensory block with slow rate of spinal anaesthetic administration ${ }^{5,6}$, some have exhibited more cephalad spread with a faster rate..$^{7,8}$ We carried out a randomized double-blind study to check the hypothesis that speed of administration of spinal anaesthetic 
( $0.75 \%$ hyperbaric bupivacaine) affects the level of maximum sensory block attained and the occurrence of adverse events like hypotension and nausea in older patients undergoing lowerlimb orthopaedic surgery.

\section{METHODS}

This is a randomized double-blind study conducted in Fauji Foundation Hospital, Rawalpindi (August 2018 to March 2019). Study was conducted after taking permission from institutional ethical review committee. Sixty patients aged 60 to 85 years in the American Society of Anaesthesiologists (ASA) physical status I, II and III undergoing lower-limb orthopaedic surgery were included in the study. Patients were randomized into two groups (fast and slow). Patients in the fast group received an intrathecal injection of $1.5 \mathrm{ml}$ of hyperbaric $0.75 \%$ bupivacaine over 5 seconds (about 0.3 $\mathrm{mL} / \mathrm{sec}$ ). Patients in the slow group received an intrathecal injection of $1.5 \mathrm{ml}$ of hyperbaric $0.75 \%$ bupivacaine over 50 seconds (about $0.03 \mathrm{~mL} / \mathrm{sec}$ ). Patients with peripheral neuropathy, neurological conditions, altered mental status, ischemic heart disease, contraindications to spinal anaesthesia and predisposition to severe hypertension, were excluded. Primary outcome was the maximum level of sensory block attained and the incidence of hypotensive episodes. Secondary outcomes included time to reach maximum height of sensory and motor block, time taken to T10 level, the degree of motor block, incidence of nausea, and the use of phenylephrine and antiemetics for hypotension and nausea respectively. Two anesthetists were involved in the procedure (the administrator and the assessor). The administrator was responsible for randomization and injecting the spinal anaesthetic according to the group assignment and the assessor was responsible for documentation of pre-specified variables. Both assessor and patient were blinded.

Spinal anaesthesia was administered in patients' midline following standard protocols of disinfection and administration of $2 \%$ lidocaine using a 25-gauge spinal needle at L3-L4 level. Patients were placed in a sitting position. 1.5 $\mathrm{ml}$ of $0.75 \%$ bupivacaine was administered over either 5 seconds (fast group) or 50 seconds (slow group). Oxygen was given at $5 \mathrm{~L} / \mathrm{min}$ through face mask. All measurements were taken at baseline then every minute for the initial 15 minutes, then every five minutes for the next 20 minutes and finally at 45 minutes. The level of sensory block was measured by the assessor using a beveled needle, sensory block level was determined by the inability to detect the pinprick sensation bilaterally.Modified Bromage score (0 to 3 ) was used to determine the extent of motor block.An automatic blood pressure monitor, and a pulse oximeter were used to measure systolic blood pressure and heart rate respectively. Hypotensive episode was defined as the incidence of systolic blood pressure falling below $100 \mathrm{mmHg}$ or a decrease of $30 \%$ or more below the patient's baseline value. IV phenylephrine (25 microgram bolusevery two minutes until blood pressure of $>100 \mathrm{mmHg}$ was achieved) was used to treat such episodes. The incidence of phenylephrine use, nausea, and antiemetic use were also documented.

\section{Statistics}

We used Wilcoxon two-sample test to compare the maximumsensory block level and maximum motor block level attained between the two groups. We used to unpaired student's t tests to compare the lowest systolic blood pressure, time needed to attain maximum sensory block level, maximum motor block level, to first hypertensive event and to lowest systolic blood pressure. Rate of hypotensive episodes and nausea were compared using Fisher's exact test. $P$ value of less than 0.05 was deemed statistically significant.

\section{RESULTS}

A total of 60 patientswas randomized in two groups of 30 patients each. All patients attained adequate level of anaesthesia. Patient demographics and baseline characteristics (including age, gender, weight, ASA classification, and baseline systolic blood pressure) were similar in both groups (Table-I).

The characteristics of spinal anaesthesia are presented in Table-II. The maximum sensory block height achieved was alike for both fast and slow groups (median $=\mathrm{T} 4$, interquartile range $=\mathrm{T} 4$ 
$T 6, P=0.77)$. There was no significant difference in time to reach maximum sensory block level $(4.2 \pm 1.5 \mathrm{~min}$ vs $3.8 \pm 1.2 \mathrm{~min}, \mathrm{P}=0.26)$ and the time to reach $\mathrm{T} 10$ sensory block level (2.5 \pm 1.17 min vs $\min$ in $2.2 \pm 0.82$ slow group, $P$ $=0.11$ ) which is the minimum level required for lower limb surgery. No difference was seen in the degree of motor block (Bromage score attained $=3$ ) and the time taken to attain maximum level of motor block $(5.9 \pm 1.4 \mathrm{~min}$ vs $5.7 \pm 1.2 \mathrm{~min}, \mathrm{P}$ $=0.56)$.

Hemodynamic characteristics after intrathecal injection can be seen in Table-III.

There was no difference in the rate of hypotension between the slow and the fast groups (fast $=8 / 30$, slow $=4 / 30, P=0.33$ ). The lowest documented systolic blood pressure (Figure-1, $109.5 \pm 16.4$ vs
$112.7 \pm 21.2, P=0.52)$ and time taken to reach it was also similar.
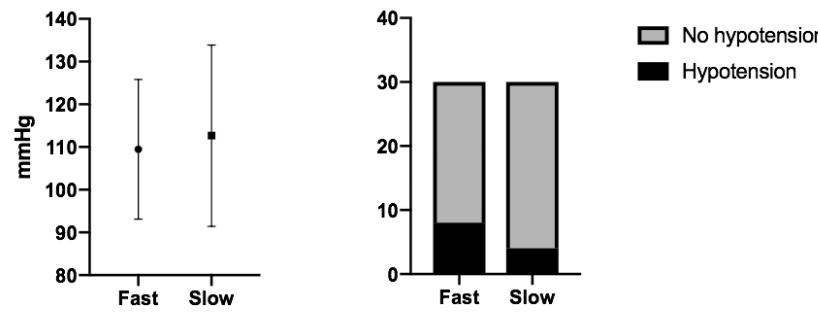

Figure-I. Lowest systolic blood pressure (left) and incidence of hypotension (right)

Total doses of phenylephrine given was also similar between group. There was no difference in the incidence of nausea (fast $=5 / 30$, slow $=$ $3 / 30, P=0.71$ ), and antiemetic use (fast $=1 / 30$, slow $=2 / 30, P=>0.99$ ) in between the groups (Table-III).

\begin{tabular}{|l|c|c|c|}
\hline \multicolumn{1}{|c|}{ Group } & Fast $(\mathbf{n = 3 0})$ & Slow $(\mathbf{n}=\mathbf{3 0})$ & P-Value \\
\hline Age (year) & $69.9 \pm 7.3$ & $72 \pm 9.1$ & 0.31 \\
\hline Male/Female $(\mathrm{n})$ & $19 / 11$ & $16 / 14$ & 0.60 \\
\hline Weight $(\mathrm{kg})$ & $63.5 \pm 9.7$ & $63.2 \pm 11$ & 0.91 \\
\hline ASA classification (n) & & & \\
\hline I & $14 / 30$ & $10 / 30$ & \\
\hline II & $13 / 30$ & $16 / 30$ & \\
\hline III & $3 / 30$ & $4 / 30$ & \\
\hline Systolic blood pressure (mmHg) & $138.3 \pm 24.7$ & $141.8 \pm 18.1$ & 0.54 \\
\hline
\end{tabular}

Table-I. Demographics and baseline characteristics

\begin{tabular}{|l|c|c|c|}
\hline \multicolumn{1}{|c|}{ Group } & Fast $(\mathbf{n = 3 0})$ & Slow $(\mathbf{n = 3 0})$ & P-value \\
\hline Maximum level of sensory block & T4 & T4 & 0.77 \\
\hline Range & (T3-T10) & (T4-T10) & \\
\hline Quartile & {$[$ T4-T6] } & [T4-T6] & \\
\hline Maximum level of motor block (Bromage score) & 3 & 3 & 0.61 \\
\hline Time to T10 sensory block level & $2.5 \pm 1.17$ & $2.2 \pm 0.82$ & 0.27 \\
\hline Time to maximum level of sensory block (min) & $4.2 \pm 1.5$ & $3.8 \pm 1.2$ & 0.26 \\
\hline Time to maximum level of motor block (min) & $5.9 \pm 1.4$ & $5.7 \pm 1.2$ & 0.56 \\
\hline
\end{tabular}

Table-II. Spinal block characteristics

\begin{tabular}{|l|c|c|c|}
\hline \multicolumn{1}{|c|}{ Group } & Fast $(\mathbf{n = 3 0})$ & Slow $(\mathbf{n}=\mathbf{3 0})$ & P-value \\
\hline Incidence of hypotension (n) & 8 & 4 & 0.33 \\
\hline Lowest SBP (mmHg) & $109.5 \pm 16.4$ & $112.7 \pm 21.2$ & 0.52 \\
\hline Time to first hypotensive episode (min) & $3.2 \pm 1.4$ & $9.1 \pm 9.3$ & 0.09 \\
\hline Total time hypotensive (min) & $4.6 \pm 1.1$ & $4.0 \pm 1.4$ & 0.41 \\
\hline Total dose of phenylephrine (mg) & $87.5 \pm 25$ & $58.3 \pm 38.2$ & 0.27 \\
\hline Phenylephrine use (n) & 5 & 3 & 0.71 \\
\hline Nausea (n) & 5 & 3 & 0.71 \\
\hline Antiemetic use (n) & 1 & 2 & $>0.99$ \\
\hline
\end{tabular}

Table-III. Hemodynamic characteristics after intrathecal injection 


\section{DISCUSSION}

In lower limb orthopaedic surgeries, regional anesthesia especially spinal anaesthesia is often preferred over general anesthesia. ${ }^{4}$ However, despite it being a simpler and faster method it is associated with a great risk of marked hypotension. While increased age is a risk factor for increased peri-operative death, presence of co-morbidities and invasiveness of surgery are also some factors that increase the chance of death in aged patients. ${ }^{9}$ As an anesthetist it is important to maintain an equilibrium between appropriate blood pressure levels and adequate block height. It is proposed that the rate of injection is an important factor in controlling this equilibrium. Several researches have supported this theory, while many have failed to find a link between speed and block height. The application of these studies was however limited by the characteristics of anaesthetics used (like type and volume) and sample population's characteristics.

In this study we hypothesized that the speed of administration of spinal anaesthetic $(0.75 \%$ hyperbaric bupivacaine) affects the level of maximum sensory block attained and the occurrence of adverse events like hypotension and nausea in older patients undergoing lower-limb orthopaedic surgery. The volume of cerebrospinal fluid and the age of patient play an important role on the spread of local anaesthetic. With age, as the volume of cerebrospinal fluid decreases, it is postulated that speed of injection of local anaesthetic solution, could, perhaps have a greater effect on the spread of anaesthesia in elderly patients. ${ }^{10}$ In an earlier study, fast rate of injection $(0.5 \mathrm{~mL} / \mathrm{s})$ of bupivacaine resulted in a more cephalad spread of spinal anaesthesia compared to the slow rate $(0.02 \mathrm{~mL} / \mathrm{s}) .{ }^{11}$ Fast rate of injection also resulted in a higher level of maximum sensory block level compared to the slow rate of injection (mean difference four segments). Our results however differed from this study. We found no significant difference between the fast and slow groups in elderly patients undergoing orthopaedic surgeries.

Prakash et al did a clinical trial similar to our study to assess the influence of two speeds of intrathecal injection of $2 \mathrm{ml}$ of $0.5 \%$ hyperbaric bupivacaine on maximum sensory block level and the incidence of adverse outcomes after operation, in senior patients undergoing transurethral surgery. ${ }^{12}$ No difference in the clinical characteristics of spinal anaesthesia was seen. In this study the intrathecal injection was performed with the patients in the lateral position. In our study, patients had similar age and ASA status (I, II or III), but intrathecal procedures were performed in sitting position compared to lateral position with a tenfold difference in speed of injection compared to an eightfold difference in speed. Moreover, we used $0.75 \%$ bupivacaine 1.5 $\mathrm{ml}$ in elderly patients for orthopaedic surgeries. Despite these differences, our results were similar to the fore-mentioned trial. In another study ${ }^{13}$, the influence of two different speeds of injection on the spread of spinal anaesthesia of in orthopaedic patients was carried out. Contrary to our study, $0.5 \%$ isobaric bupivacaine with sufentanyl was used. The slower speed lead to significantly decreased incidence and severity of hypotension.

No difference in the levels of sensory anaesthesia, and the incidence of hypotension and nausea was observed in the first randomized doubleblind clinical trial assessing the effects of a tenfold difference in speed of intrathecal hyperbaric bupivacaine administration in pregnant patients undergoing Caesarian section. ${ }^{14}$ These results were similar to our findings in spinal anaesthesia for elderly patients for lower limb orthopaedic surgeries.

A potential limitation of our study is manual administration of spinal anaesthesia which may have led to less uniform administration compared to electronic pumps which are more accurate.

\section{CONCLUSION}

The speed of injection does not affect clinical characteristics of spinal anaesthesia in elderly patients getting $0.75 \%$ hyperbaric bupivacaine. There is no significant difference in hemodynamic changes or spread of spinal anaesthesia based on speed.

Copyright@ 15 July, 2019. 


\section{REFERENCES}

1. Nagaratnam N, Nagaratnam K, Cheuk G, editors. Advanced Age Geriatric Care: A Comprehensive Guide. Springer; 2018 Nov 26.

2. Bidikar M, Mudakanagoudar MS, Santhosh MCB. Comparison of Intrathecal Levobupivacaine and Levobupivacaine plus fentanyl for cesarean section. Anesthesia, essays and researches. 2017; 11(2):495-8.

3. Hofhuizen C, Lemson J, Snoeck M, Scheffer G-J. Spinal anesthesia-induced hypotension is caused by a decrease in stroke volume in elderly patients. Local and regional anesthesia. 2019; 12:19-26.

4. Magar JS, Bawdane KD, Patil R. Comparison of efficacy and safety of unilateral spinal anaesthesia with sequential combined spinal epidural anaesthesia for lower limb orthopaedic surgery. Journal of clinical and diagnostic research: JCDR. 2017; 11(7):Uc17-uc20.

5. Janik R, Dick W, Stanton-Hicks M. The effect of the injection speed on the blockade characteristics of hyperbaric bupivacaine and tetracaine in spinal anesthesia. Regional-Anaesthesie. 1989; 12(4):63-8.

6. Tuominen M, Pitkanen M, Rosenberg PH. Effect of speed of injection of $0.5 \%$ plain bupivacaine on the spread of spinal anaesthesia. British journal of anaesthesia. 1992; 69(2):148-9.

7. Chin KW, Chin NM, Chin MK. Spread of spinal anaesthesia with $0.5 \%$ bupivacaine: influence of the vertebral interspace and speed of injection. The Medical journal of Malaysia. 1994; 49(2):142-8.
8. Atchison SR, Wedel DJ, Wilson PR. Effect of injection rate on level and duration of hypobaric spinal anesthesia. Anesthesia and analgesia. 1989; 69(4):496500.

9. Akhtar S. Pharmacological considerations in the elderly. Current opinion in anaesthesiology. 2018; 31(1):11-8.

10. Greene NM. Distribution of local anesthetic solutions within the subarachnoid space. Anesthesia and analgesia. 1985;64(7):715-30.

11. Horlocker TT, Wedel DJ, Wilson PR. Effect of injection rate on sensory level and duration of hypobaric bupivacaine spinal anesthesia for total hip arthroplasty. Anesthesia and analgesia. 1994; 79(4):773-7.

12. Prakash S, Bhartiya V, Pramanik V, Pahilajani J, Gogia AR, Singh R. The effect of injection speed on the spinal block characteristics of hyperbaric bupivacaine $0.5 \%$ in the elderly. Journal of anesthesia. 2010; 24(6):877-81.

13. Mirea L, Ungureanu R, Burtea R, Pavelescu D, Grintescu I. Effect of injection speed on hypotension associated with spinal anesthesia for orthopedic surgery in elderly patients: 8AP3-6. European Journal of Anaesthesiology (EJA). 2012; 29.

14. Singh SI, Morley-Forster PK, Shamsah M, Butler R. Influence of injection rate of hyperbaric bupivacaine on spinal block in parturients: A randomized trial. Canadian journal of anaesthesia $=$ Journal canadien d'anesthesie. 2007; 54(4):290-5.

\begin{tabular}{|c|c|c|c|}
\hline \multicolumn{4}{|c|}{ AUTHORSHIP AND CONTRIBUTION DECLARATION } \\
\hline Sr. \# & Author-s Full Name & Contribution to the paper & Author $=$ s Signature \\
\hline 1 & $\begin{array}{l}\text { Manzoor Ahmed Faridi } \\
\text { (Retd) }\end{array}$ & Major Research work. & \\
\hline 2 & Shaheen Mehmood & $\begin{array}{l}\text { Helping in research work and } \\
\text { collection of data. }\end{array}$ & \\
\hline 3 & M. Safi Ur Rehman & $\begin{array}{l}\text { Helping in research work and } \\
\text { collection of data. }\end{array}$ & \\
\hline
\end{tabular}

